\title{
Failure of splenectomy to ameliorate portal hypertension in myeloproliferative disorders
}

\author{
SAMUEl S LEe MD, GUIDO VAN ROSENDAAL MD, THOMAS E LAY MD, \\ JAMES K KELLY MB, GRAHAM F PINEO MD
}

SS LeE, G VAN RosendaAl, TE LAy, JK Kelly, GP PINEO. Failure of splenectomy to ameliorate portal hypertension in myeloproliferative disorders. Can J Gastroenterol 1994;8(2):97-100. The correct treatment of portal hypertension associated with myeloproliferative disorders remains uncertain. Splenectomy has been advocated by some to eliminate the forward flow component of the portal hypertension and thus reduce portal pressure. The authors describe three recent cases of myeloproliferative disorder in whom splenectomy failed to achieve any significant amelioration of portal hypertension, with in-depth hemodynamic studies in one patient. Based on these experiences, the authors suggest that splenectomy is not the optimum treatment of the portal hypertension associated with myeloproliferative disorders.

Key Words: Backward flow, Blood dyscrasia, Forward flow, Nodular regenerative hyperplasia

\section{Échec de la splénectomie à améliorer l'hypertension portale dans les maladies myéloprolifératives}

RÉSUMÉ : Le traitement adéquat de l'hypertension portale associée aux maladies myéloprolifératives demeure incertain. La splénectomie a été favorisée par certains chercheurs en vue d'éliminer la composante de débit efférent de l'hypertension portale et de réduire ainsi la pression dans la veine porte. Les auteurs décrivent trois cas récents de maladie myéloproliférative au cours desquels la splénectomie fut incapable d'engendrer quelque amélioration significative que ce soit de l'hypertension portale, ce, démontré au moyen d'études hémodynamiques approfondies chez un patient. Sur la base de ces expériences, les auteurs suggèrent que la splénectomie ne soit pas le meilleur traitement de l'hypertension portale associée aux maladies myéloprolifératives.

Departments of Medicine and Pathology, University of Calgary, Calgary, Alberta

Correspondence: Dr SS Lee, 3330 Hospital Drive NW, Calgary, Alberta T2N 4N1.

Telephone (403) 220-8457, Fax (403) 283-3028

Received for publication March 25, 1993. Accepted July 26, 1993
$\mathrm{M}$ YELOPROLIFERATIVE DISORDERS occasionally are associated with portal hypertension (1-9). Indeed, consequences of the portal hypertension, such as esophageal variceal bleeding and ascites, often become the dominant clinical features in these patients. The pathogenesis of portal hypertension in these cases is unknown. Previous studies had suggested that splenomegaly and consequent increased splenic bloodflow augmented portal pressure $(10,11)$, which led some to propound splenectomy as a treatment for portal hypertension in various hematological diseases. We have treated three patients with myeloproliferative disorder and portal hypertension in whom splenectomy had no effect on the course of portal hypertension. Detailed hemodynamic studies were done on one patient.

\section{CASE PRESENTATIONS}

Case 1: A 60-year-old Caucasian male was admitted to hospital with hematochezia. He had been generally well until one year before admission, when ascites and splenomegaly were noted. Past history included adult-onset diabetes and 
recurrent duodenal ulcers which responded to vagotomy and pyloroplasty.

A computed tomographic scan done four months before admission showed an enlarged portal vein, splenic and paragastric varices, and cholelithiasis. A tentative diagnosis of 'cryptogenic cirrhosis' was made, but liver biopsy was not done because of the ascites.

Physical examination revealed ascites, peripheral edema and massive splenomegaly. The remainder of the examination was unremarkable; stigmata of chronic liver disease were $a b$ sent and the liver could not be palpated.

His hemoglobin was $112 \mathrm{~g} / \mathrm{L}$, white blood cell count was $15.0 \times 10^{9} / \mathrm{L}$ and platelet count was $687 \times 10^{9} / \mathrm{L}$. The diagnosis of myelofibrosis was made from examination of the blood smear and bone marrow biopsy. Gastroscopy done shortly after admission confirmed a bleeding origin from esophageal varices.

One month after admission, the patient had a splenectomy in an effort to ameliorate the portal hypertension. At laparotomy, the liver was noted to be faintly nodular and firm but did not demonstrate any gross evidence of cirrhosis. A needle biopsy of the liver revealed nodular regenerative hyperplasia. The histology of the spleen was typical of myelofibrosis. The postoperative course was complicated by marked thrombocytosis which was treated by leukapheresis and hydroxyurea.

On the sixth postoperative day, the patient had a further variceal hemorrhage, and demonstrated worsening of the ascites and peripheral edema. The possibilities of hepatic or portal vein thrombosis as a consequence of thrombocytosis were entertained, but Doppler ultrasound scanner was not available.

Over the next four weeks, despite aggressive medical treatment, the patient deteriorated. He continued to have recurrent variceal bleeding, increasing ascites and fluid retention, and died on the 34 th postoperative day. Permission for autopsy was refused.

Case 2: A 67-year-old Caucasian male was admitted with hematemesis. Three years previously, the diagnosis of myelofibrosis had been made after he presented with uncontrolled bleeding following dental extraction, and he had thrombocytosis and leukocytosis (bone marrow biopsy confirmed the diagnosis). Past history also included hypothyroidism and gout.

Physical examination showed pallor of the skin, splenomegaly, ascites and evidence of hypothyroidism. The remainder of the examination was unremarkable.

His hemoglobin was $70 \mathrm{~g} / \mathrm{L}$, white blood cell count was $54.0 \times 10^{9} / \mathrm{L}$ and platelet count was $82 \times 10^{9} / \mathrm{L}$. Technetium liver scan and ultrasound of the liver were normal aside from splenomegaly and ascites. Gastroscopy revealed large esophageal varices and angiography showed a grossly dilated portal venous system and splenomegaly with dilated splenic artery. No thromboses were seen.

After admission, hematemesis ceased spontaneously and the ascites resolved with diuretic therapy. Percutaneous liver biopsy demonstrated changes consistent with early nodular regenerative hyperplasia.

In view of the portal hypertension and thrombocytopenia, a splenectomy and a proximal splenorenal shunt were done. Postoperatively, the patient made a good recovery and was discharged. He was readmitted four times in the following two years with further episodes of variceal bleeding, which stopped either spontaneously or with endoscopic sclerotherapy. Patency of the splenorenal shunt could not be determined noninvasively, and he refused further angiography.

On the patient's final admission, variceal bleeding did not stop spontaneously. He refused sclerotherapy, but consented to esophageal transection, which stopped the bleeding. He was initially well postoperatively, but then developed fever and suspected intraabdominal sepsis. The patient died with multisystem organ failure, and consent for autopsy was refused.

Case 3: A 78-year-old Caucasian female was admitted for investigation of hypersplenism. She complained of pruritus, weakness, night sweats and fever. Other than a history of remote self- limited hepatitis with no obvious sequelae, there was no history of liver disease.

Physical examination revealed small, firm lymph nodes in the left anterior cervical chain and massive splenomegaly with an overlying bruit. The skin was excoriated. The reminder of the examination was normal.

Her hemoglobin was $82 \mathrm{~g} / \mathrm{L}$, white blood cell count was $2.2 \times 10^{9} / \mathrm{L}$ and platelet count was $240 \times 10^{9} / \mathrm{L}$. She was iron deficient. A bone marrow biopsy showed hypercellularity and increased reticulin but no sign of malignancy. The patient was discharged on oral iron therapy with a diagnosis of myelodysplastic syndrome.

Three months later, she was readmitted with hematemesis and melena, and was found to have large esophageal varices on endoscopy. The bleeding stopped with sclerotherapy. Because of the disappointing experience with the two previous cases, the authors felt that complete hemodynamic assessment would be useful before considering any further interventions. Accordingly, the patient was readmitted one month later for a transjugular liver biopsy and hepatic hemodynamic studies. The hepatic venous pressure gradient was elevated at $12 \mathrm{mmHg}$ (wedged and free hepatic venous pressures were 20 and 8 $\mathrm{mmHg}$, respectively). The cardiac output was slightly elevated at $6.6 \mathrm{~L} / \mathrm{min}$. A splenoportogram revealed patency of the splenic and portal veins, and extensive portosystemic collateral formation. The splenic pulp pressure was 24 $\mathrm{mmHg}$. The biopsy specimen was fragmented but consistent with nodular regenerative hyperplasia.

In view of the cytopenia, thought to be due to hypersplenism, and the possibility of ameliorating the portal hypertension, the patient was booked for splenectomy. One month after the hemodynamic studies, a splenectomy and a proximal splenorenal shunt were done. Prior to the shunting procedure, the intraoperative portal pressure was $21 \mathrm{mmHg}$; this fell to $11 \mathrm{mmHg}$ after the anastomosis was created. Histology of the spleen revealed a large cleavedcell follicular lymphoma. An operative wedge biopsy of the liver confirmed the 
presence of nodular regenerative hyperplasia (Figure 1).

Postoperatively, a computed tomographic scan of the abdomen revealed portal vein thrombosis. Endoscopy showed small esophageal varices but when repeated three days later, the varices had regrown to their preoperative size. Therefore, three weeks after the initial operation, a side-to-side portocaval shunt bypassing the portal vein thrombosis was performed. The portal pressure before the shunt was established was $22 \mathrm{mmHg}$; after the anastomosis it fell to $8 \mathrm{mmHg}$. The postoperative course was uneventful and two weeks after the second operation, varices were absent on repeat endoscopy. Doppler ultrasound showed flow in the portocaval shunt although the clot was still present.

After a course of intravenous heparin, the patient was discharged on oral warfarin. Repeat endoscopy one year later revealed no esophageal varices. Her current hemogram, including white blood cell and platelet counts, is within normal limits. Because her symptoms are quite indolent, she is not undergoing chemotherapy for her lymphoma, and has demonstrated no evidence of liver failure, with no further bleeding during the two-year follow-up.

\section{DISCUSSION}

The best treatment for portal hypertension in patients with myeloproliferative disorder remains unclear, but splenectomy has been advocated by some, based on anecdotal reports and theoretical reasons why it should be effective. Based on our experience with the three presented cases and review of the theoretical aspects, we disagree with this notion.

The pathogenic mechanisms inducing portal hypertension in myeloproliferative disorders are still unknown. Earlier studies indicated that the massive splenomegaly in myeloproliferative disorders is associated with increased splenic bloodflow: up to 1.5 $\mathrm{L} / \min (10,11)$.

Because portal pressure $(\mathrm{P})$ is the product of portal venous flow (Q) and intrahepatic portal resistance (R), according to the formula $\mathrm{P}=\mathrm{QxR}$, it

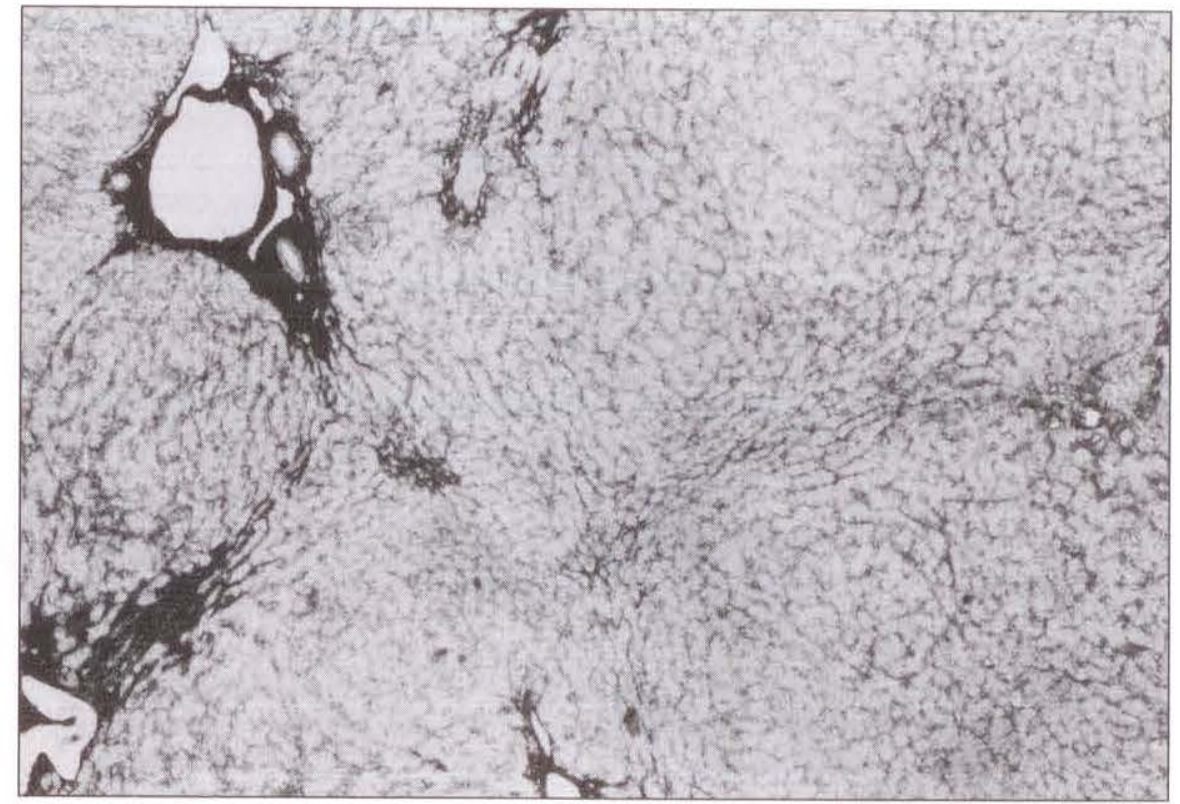

Figure 1) Liver biopsy from case 3. The sirius red stain for connective tissue shows portions of several parenchymal nodules separated by compressed liver cells but not by fibrous septa, typical of nodular regenerative hyperplasia

would be expected that increasing flow into the portal venous system would also increase portal pressure. This is known as the 'forward flow' mechanism $(1,11)$, while the 'backward flow' mechanism comprises factors that increase resistance. It is generally accepted that most forms of portal hypertension in humans are due to a combination of the two factors. Since it appears that hepatic sinusoidal circulation is intermittent, with only 20 to $25 \%$ of sinusoids being perfused at any instant, hepatic vascular reserve capacity is considerable (12). This explains experimental data that show that huge increments in flow, even doubling or trebling flows, result in only modest increases in portal pressure $(13,14)$. Thus it appears that only under exceptional circumstances can forward flow - by itself - cause significant portal hypertension. Interestingly, the forward flow idea led some workers to try splenectomy in portal hypertension due to cirrhosis three to four decades ago. However, the complete lack of efficacy led to abandonment of this procedure.

Myeloproliferative disorders are known to be associated with increased clotting risk, and operative intervention in particular carries high risk of thromboses in the portal venous system. In two of our cases there was circumstantial evidence, and in the third, proof of clots in the portal system.

Recent studies have shown that the liver is abnormal, even when not infiltrated by tumour cells, in myeloproliferative disorders. The sinusoids may show subtle morphological changes predisposing to portal hypertension, such as perisinusoidal fibrosis or collagenization of the Disse space (15)

Wanless and colleagues (16) found that hepatic microvascular thrombi are much more common than previously thought, with $40 \%$ of autopsied cases of myeloproliferative syndrome showing these lesions. Such abnormalities likely lead to presinusoidal and sinusoidal portal hypertension and nodularity, as typified by nodular regenerative hyperplasia. This lesion was present in all three of our cases. Since nodular regenerative hyperplasia has been well defined only within the past decade (17), one might speculate that some of the previous reported cases of portal hypertension in hematological disorders may have been unrecognized examples of this condition. Nodular regenerative hyperplasia causes portal hypertension predominantly by backward flow mechanisms (sinusoidal compression 
by nodules and vascular distortion), with a lesser contribution by forward flow (splenomegaly with increased splenic bloodflow) (18).

Finally, there appears to be an inverse inter-relationship between splenic and superior mesenteric venous flow such that overall portal venous flow tends to remain constant. Studies by Moriyasu and colleagues in patients with portal hypertension, using a duplex Doppler system, show that splenectomy or transient occlusion of the splenic artery leads to augmentation of

\section{REFERENCES}

1. Shaldon S, Sherlock S. Portal hypertension in the myeloproliferative syndrome and the reticuloses. Am J Med 1962;32:758-64.

2. Rosenbaum DL, Murphy GW, Swisher $\mathrm{SN}$. Hemodynamic studies of the portal circulation in myeloid metaplasia. Am J Med 1966;41:360-8.

3. Ward HP, Block MH. The natural history of agnogenic myeloid metaplasia (AMM) and a critical evaluation of its relationship with the myeloproliferative syndrome. Medicine 1971;50:357-411.

4. Glew RH, Haese WH, McIntyre PA. Myeloid metaplasia with myelofibrosis: The clinical spectrum of extramedullary haematopoiesis and tumor formation. Hopkins Med J 1973;132:253-65.

5. Sullivan A, Rheinlander $\mathrm{H}$, Weintraub LR. Esophageal varices in agnogenic myeloid metaplasia: Disappearance after splenectomy. Gastroenterology 1974;66:429-32.

6. Schwartz SI. Myeloproliferative disorders. Ann Surg 1975;182:464-71.

7. Lukie BE, Card RT. Portal hypertension complicating myelofibrosis:reversal following splenectomy. Can Med Assoc J 1977;117:771-2

8. Silverstein MN, ReMine WH. Splenectomy in myeloid metaplasia. Blood 1979;53:515-9. superior mesenteric venous flow, and a lower than expected decrease in portal pressure $(19,20)$. Therefore, the overall impact of decreases in splenic bloodflow to the forward flow component of portal pressure will be blunted.

The outcome of splenectomy in our patients is at odds with several previous reports of successful eradication of varices after splenectomy in myeloproliferative disorders (5-8). However, portosystemic collaterals are well known to arise in sites of intrabdominal surgery, and one wonders to what ex-

9. Shorey J, Weinberg MN, Frenkel EP, Fallis BD. Nodular regenerative hyperplasia of the liver in a case of myelofibrosis with extramedullary haematopoiesis and secondary portal venous hypertension. Am J Clin Path 1979;72:122-5.

10. Paraf A, Chalut J, Caroli J, Porcher P. Manometrie splenique et splenoportographie dans les affections du systeme hemopoietique, les pylephlebites, les cirrhoses du foie. Rev Int Hepatol 1955;5:617-61.

11. Blendis LM, Banks DC, Ramboer C, Williams R. Spleen blood flow and splanchnic haemodynamics in blood dyscrasia and other splenomegalies. Clin Sci 1970;38:73-84.

12. Rappaport AM, Knoblauch M, Black RG, Ohira S. Hepatic microcirculatory changes leading to portal hypertension. Ann NY Acad Sci 1970;170:48-66.

13. Witte CL, Tobin GR, Clark DS, Witte MH. Relationship of splanchnic blood flow and portal venous resistance to elevated portal pressure in the dog. Gut 1976;17:122-6.

14. Lee SS, Hadengue A, Girod C, Braillon A, Lebrec D. Reduction of intrahepatic vascular space in the pathogenesis of portal hypertension. Gastroenterology 1987;93:157-61.

15. Roux D, Bioulac-Sage P, Merlio JP, Lamouliatte $\mathrm{H}$, Quinton A, Balabaud tent this possible route of decompression may have contributed to the outcomes in those cases where varices had disappeared. Since complete hemody. namic studies, including measurement of portal pressure, and hepatic and splenic bloodflow after splenectomy have not yet been done in a series of patients, these issues are still unsettled. However, for the reasons detailed above, we feel that splenectomy alone is not an effective treatment for portal hypertension associated with myeloproliferative disorders.

C. Liver sinusoids and sinusoidal cells in patients with agnogenic myeloid metaplasia. J Clin Gastroenterol 1987;9:483-7.

16. Wanless IR, Peterson P, Das A, Boitnott JK, Moore GW, Bernier V. Hepatic vascular disease and portal hypertension in polycythemia vera and agnogenic myeloid metaplasia: A clinicopathological study of 145 patients examined at autopsy. Hepatology 1990;12:1166-74.

17. Wanless IR, Godwin TA, Allen F, Feder A. Nodular regenerative hyperplasia of the liver in hematologic disorders: A possible response to obliterative portal venopathy. Medicine 1980;59:367-79.

18. Blendis LM, Parkinson MC, Shilkin KB, Williams R. Nodular regenerative hyperplasia of the liver in Felty's syndrome. Quart J Med 1974; 169:25-32.

19. Moriyasu F, Nishida O, Ban N. et al. Ultrasonic doppler duplex study of hemodynamic changes from portosystemic shunt operation. Ann Surg 1987;205:151-6.

20. Nishida O, Moriyasu F, Nakamura T, et al. Interrelationship between splenic and superior mesenteric venous circulation manifested by transient splenic arterial occlusion using a balloon catheter. Hepatology 1987;7:442-6. 


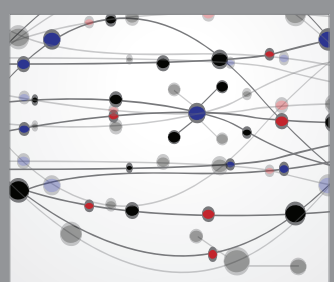

The Scientific World Journal
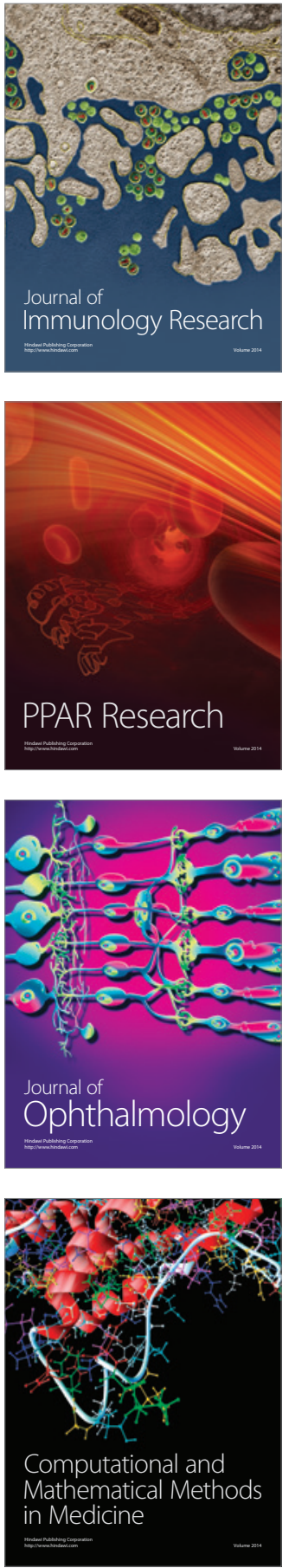

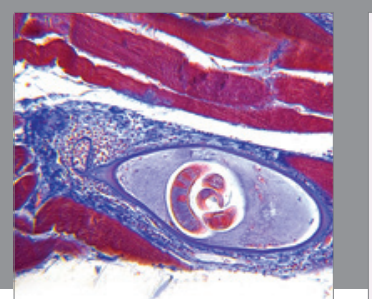

Gastroenterology Research and Practice

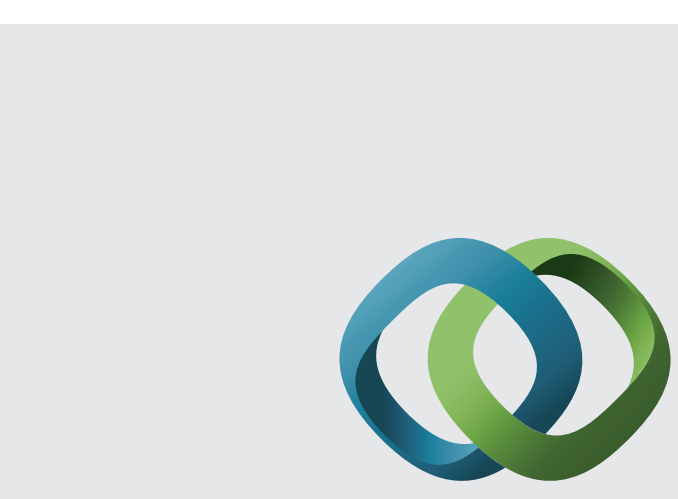

\section{Hindawi}

Submit your manuscripts at

http://www.hindawi.com
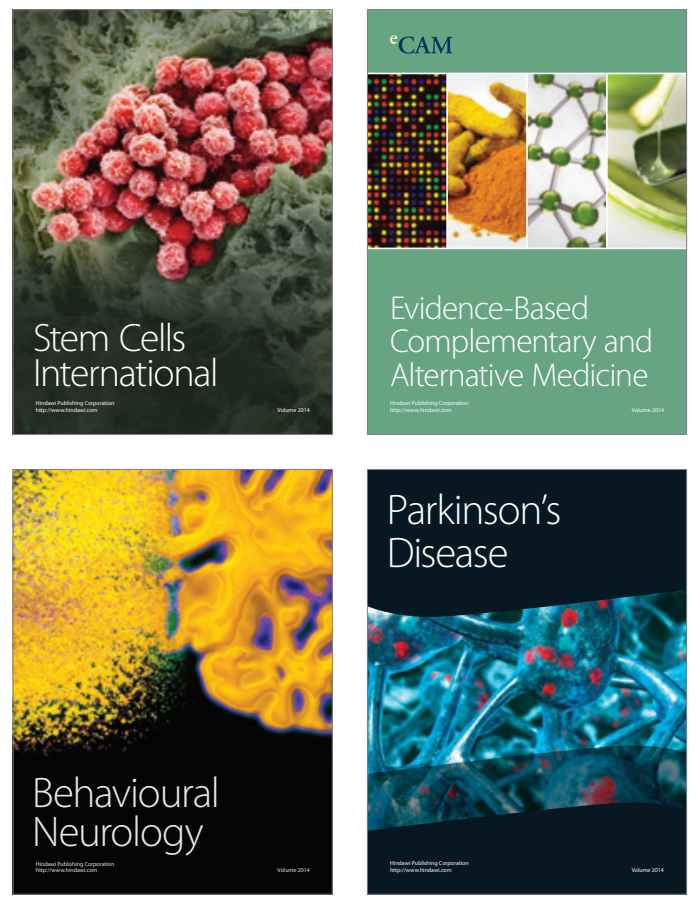
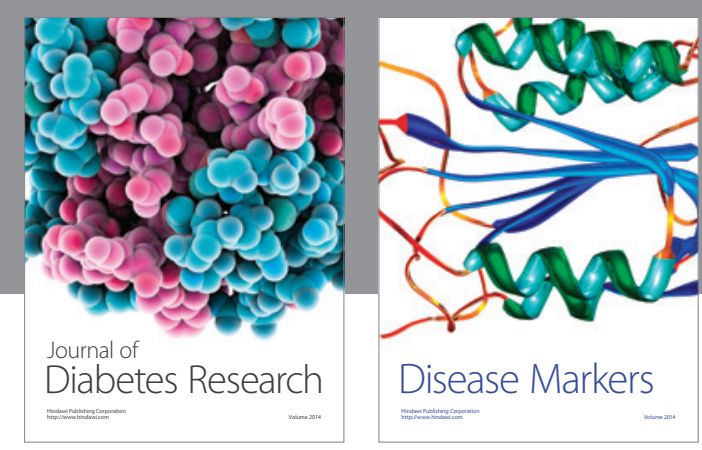

Disease Markers
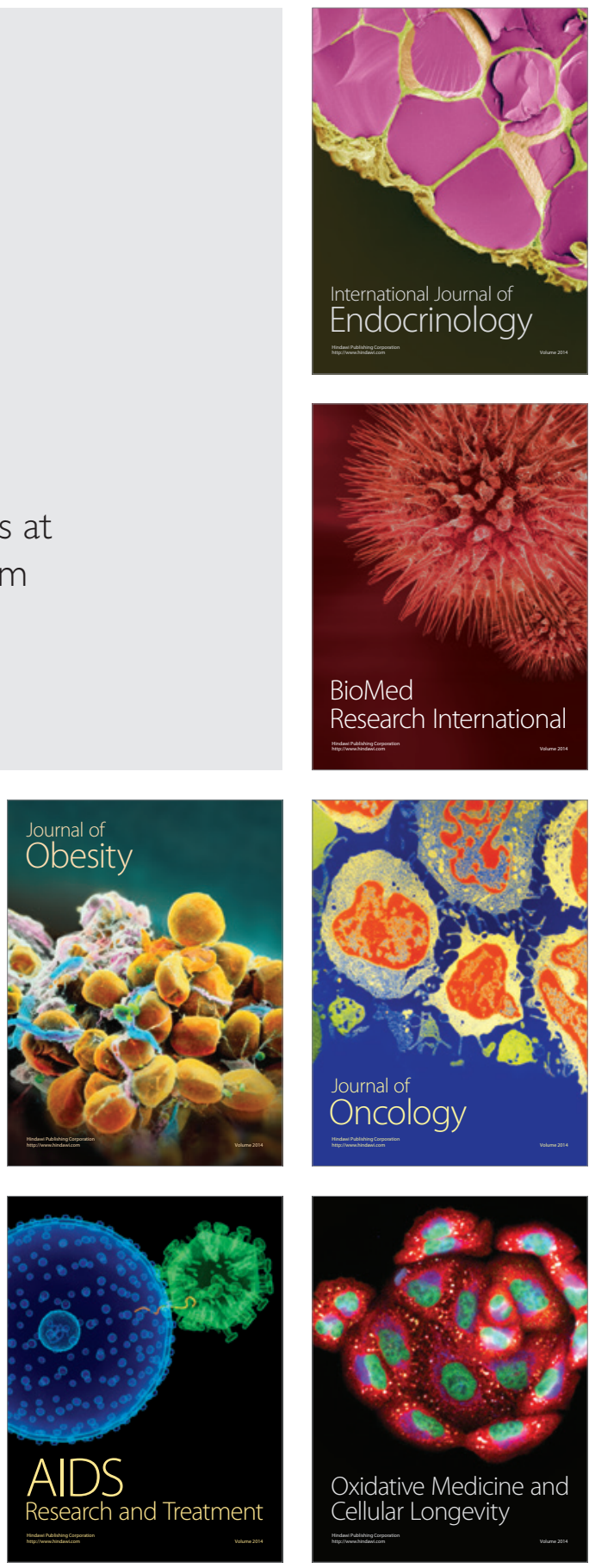